\title{
ITALO CALVINO E A ENERGIA "NO MOMENTO DO INÍCIO"
}

\author{
Fabio Pierangeli* \\ Università di Roma-Tor Vergata
}

Resumo: O incipit, como exórdio narrativo, como estrutura literária sobre a qual tanto reflete Calvino, contém o germe de uma sutil utopia: encontrar-se sempre no ponto de origem, no lugar criativo em que tudo é ainda possível, do qual emanam e se recolhem as energias. O iniciar, que é parte fundamental de todo projeto literário, torna-se uma experiência diretamente ligada ao indivíduo e à sua ação social-política. $\mathrm{O}$ incipit pode ser ao mesmo tempo considerado, utilizando uma terminologia da crítica estilística, um prototema arquetípico da literatura. O "ideal utópico" consistiria na dilatação contínua desta energia inicial para formar um organismo compacto, coeso, bem definido e, ao mesmo tempo, sempre novo. Sempre mais conscientemente, como atesta o ensaio Cominciare e finire [Começar e terminar], de fevereiro de 1985, esta ideia atravessa as escolhas estilísticas de Calvino, nas suas contínuas mudanças de rota, no horror de ser classificado em alguma "gaiola" intelectual ou de gênero literário.

Palavras-chave: Italo Calvino. Incipit. Energia potencial. Organismo

Tenho medo de me repetir, em minhas obras. Por esse motivo, toda vez devo criar para mim um novo desafio para enfrentar. Devo encontrar algo para fazer que pareça uma novidade, e esteja um pouco além dos meus recursos. (WEAVER; PETTIGREW, 2003, p. 63)

É possível que "de todas as coisas o que conta seria apenas o momento em que começam?" (Calvino, 2002, p. 21). Em O dia de um escrutinador, o conto de Italo Calvino do

EY NC ND Esta obra está licenciada sob uma Licença Creative Commons.

\footnotetext{
* Fabio Pierangeli é professor na Facoltà di Lettere e Filosofia da Università degli Studi di Roma "Tor Vergata", onde vem se dedicando especialmente a disciplinas sobre literatura de viagem e literatura italiana contemporânea. Participa como redator e editor de diversas publicações da área. Entre seus livros recentes: Esplorazioni leopardiane (Manziana, Vecchiarelli, 2008); Destini e identitàromane da D'Annunzio ai contemporanei (Roma, Edilet, 2008); Pavese in teatro, (Roma: Nuova Cultura, 2008); In attesa della Festa. Lettureed esercizi dai laboratori di creatività (Roma: Universitalia, 2009); Il viaggio nei classici italiani (Firenze: Le Monnier, 2011); La novella italiana, dalla Scapigliatura al verismo verso il Novecento (Milano: Unicopli, 2011), Cronache dai Big Bang, gli incipit della letteratura mondialeraccontati dagli scrittori di oggi (com Lidia Sirianni, Hacca, 2012). Atualmente prepara um volume sobre Ungaretti jornalista e sobre Stanislao Nievo. É um dos coordenadores de um projeto desenvolvido pela Università Tor Vergata e pelo presídio de Rebibbia, em Roma, que deu origem à coleção Il Vagabondo delle stelle, cujo primeiro título é Afferrare le redini di una vita nuova.

${ }^{1}$ Tradução de nossa autoria N.T.
} 
qual foi retirada a citação, Amerigo Ormea, o escrutinador comunista chamado para representar o seu partido na eleição sobre a "leggetruffa", em 1953, expõe por tese e antítese, raramente chegando a uma síntese, os seus contrastantes pensamentos, de fronte às criaturas infelizes, dementes ou acometidas por várias deficiências, hóspedes da benemérita instituição da capital piemontesa, o Cottolengo.

Aquele contexto caridoso teria, com os anos, adquirido um aspecto negativo, acusado pela parte adversária de ser um depósito fraudulento de votos democristãos, visto que pessoas incapazes (mas será assim mesmo?) de entender e querer são acompanhadas pelos religiosos dentro da cabine eleitoral, que se atribuem a tarefa de representar a vontade delas.

Calvino-Ormea se interroga sobre o direito de voto que traz consigo a pergunta bem mais radical sobre o direito à vida (que acaba por envolver ele mesmo, quando, ao telefone, a namorada lhe anuncia estar esperando um bebê e ele pensa imediatamente em aborto), partindo de uma inteligente constatação: a impossibilidade de reproduzir-se a partir de um impulso positivo bom, seja no campo comunista, seja no campo católico, capaz de gerar um movimento, agremiações políticas e sindicais realmente empenhadas em uma renovação para a reconstrução da Itália no imediato pós-guerra. Aquele impulso estava já, passada menos de uma década, desaparecendo em disputas burocráticas de todo tipo:

Então, de todas as coisas o que conta seria apenas o momento em que começam, quando todas as energias estão retesadas, quando só existe o futuro? Não chegar, para todo organismo, o momento em que o hábito, a rotina diária ganham lugar? (CALVINO, 2002, p. 21)

Com frases análogas às Notas às reedições dos seus contos precedentes, Calvino descreve a paixão social que o havia envolvido na militância, destacando a perspectiva de esperança e mudança:

Assim, na memória, ele começou a contrapor ao cenário que lhe estava diante dos olhos o clima que existia na Itália após a libertação, por uns dois anos, cuja lembrança mais viva, parecia-lhe agora, era a participação de todos nas coisas e nos atos da política, nos problemas daquele momento, graves e elementares (eram pensamentos daquele mesmo instante: naquela época, vivera aqueles tempos com um clima natural, como todos faziam, desfrutando - depois de tudo o que acontecera, aborrecendo-se com o que não estava certo, sem nunca pensar que em algum momento poderia vir a ser idealizado); lembrava o aspecto das pessoas de então, todos pareciam igualmente pobres, e mais interessados nas questões universais do que nas particulares; lembrava das sedes improvisadas dos partidos, cheias de fumaça, do ruído dos mimeógrafos, de pessoas encapotadas que competiam no impulso voluntário (e tudo isso era verdade, mas só agora, na distância dos anos, ele podia começar a enxergar, a formar uma imagem daquilo, um mito). (CALVINO, 2002, p. 19-20) 
O "mito" é ver pessoas nas quais em sua atividade brilha um mesmo desejo, um mesmo empenho, voluntário. A unidade das intenções, a convergência dos interesses, aquele movimento comum, feliz, que permite caminhar juntos em direção a um fim que se vislumbra como bom, investindo utilmente o tempo. "O aspecto" das pessoas é fervoroso, quase com naturalidade, abandonam-se os interesses privados pelo bem comum. Aquela época (note-se a particular ênfase da palavra, referível a algo de irrepetível na história social como naquela pessoal): "já tinha terminado, e aos poucos a sombra cinzenta do Estado burocrático tornara a invadir a área, igual antes durante e depois do fascismo, a velha separação entre administradores e administrados" (Calvino, 2002, p. 20). Uma nova palavra entra na linguagem simples daquela geração ativa nas sedes de partido: "melancolia".

Como é evidente, a experiência do iniciar envolve a ação social-política, a existência do indivíduo, o projeto literário. O escritor narra a sua juventude, o momento de uma energia produtiva na qual não via separação entre o seu ofício de escritor e a atividade de engajamento social. Fotografa aquilo que ficará, para sempre, o momento inicial de uma utopia, depois cultivada, renovada, no mundo escritura, mas nunca mais reapresentada com as mesmas características na experiência civil.

Substancialmente, Calvino resolve o impasse de Amerigo (o nome de um grande viajante) Ormea (sobrenome tipicamente piemontês: inércia e viagem do conhecimento) através de duas imagens, memoráveis, muito conhecidas pelos leitores de Calvino. A primeira de caráter literário e mental, aquela utopia descontínua ${ }^{2}$, mais vezes repetida e dilatada sucessivamente, nas imagens da cidade imperfeita, onde, em um momento fulminante pode aparecer o instante da perfeição.

A segunda deriva da pura observação de um contexto caridoso, sublime: o amor entre um pai e um filho "deficiente", proximidade sem palavras, cadenciada somente pela necessidade do velho agricultor de existir, sem nada mais.

Toda militância, seja ela derivada das melhores intenções e, quem sabe, admirada por Ormea, não atinge a laica pietas desta relação: o pai não escolheu estar ali, e está ali, com paciência e amor. As freiras e os próprios companheiros de partido se engajam na sociedade, a favor dos marginalizados, por uma maior justiça social, em virtude de uma livre opção.

A imitação do mecanismo mutável das cidades descontínuas nos espaços literários se baseia em adequados e promissores começos narrativos, livres e voluntários, enquanto a constante paciência do pai se compõe da lentidão de gestos monótonos, repetidos

\footnotetext{
${ }^{2}$ Necessária a referência ao texto crítico de Claudio Milanini, L'utopia discontinua, Milano, Garzanti, 1990.
}

Anu. Lit., Florianópolis, v. 20, n. Esp 1, p. 10-23, 2015. ISSNe 2175-7917 
infinitamente, gratuitamente doados por amor. Gesto que a narração pode somente descrever, circundando-o de silenciosa admiração.

Os trechos citados desse conto, entre os livros mais significativos de Calvino, desenham uma grande praça, uma rotatória, de onde bifurcam estradas largas, estatais, trilhas intricadas de montanha degradantes rumo ao mar, que conduzem a outros lugares do longo itinerário narrativo de Calvino. Aqui nos interessa retomar a sugestiva imagem do início, entre impulso existencial e acontecimentos narratológicos.

Considero propriamente o incipit um prototema arquetípico da literatura, um dos motivos caros à crítica estilística, nos quais se evidencia a ligação entre a estrutura literária e o ponto de vista do escritor sobre a própria atualidade e sobre a história.

Relação não mecânica, rica de nuances e de variáveis, nas quais o estudioso se encontra, felizmente, a analisar cada autor.

Incipit, portanto, como exórdio narrativo, sobre o qual tanto reflete Calvino, e desejo de novidade, de mudança, que contém o germe de uma sutil utopia: encontrar-se sempre no ponto de origem, no lugar criativo em que tudo é ainda possível, do qual emanam e se recolhem as energias. O "ideal utópico" consistiria na dilatação contínua desta energia inicial para formar um organismo compacto, coeso, bem definido e, ao mesmo tempo, sempre novo.

Energia e organismo, como vimos em $O$ dia de um escrutinador, parecem, ao invés, os polos muito distantes de uma dialética que, transformando-se, atravessa as várias fases da narrativa de Calvino.

A experiência histórica do pós-guerra ${ }^{3}$, como mito não mais atingível, que produziu admiráveis contos, frescos, cheios de ritmo e situações insólitas (com incipit brilhantes, colhendo, in media res, um correlativo objetivo muito eficaz), a própria infância para a criança que não quer crescer, adequando-se à rotina diária da vida adulta, a viagem como partida sempre nova em busca de alguma coisa obscura ou pouco provável, a predileção pelo conto do nascimento do cosmo antes do Big Bang e, vice-versa, no último livro, a perspectiva do renascimento depois da destruição do universo, tema caro à literatura, vivido em modo estranho, cândido, por Palomar: esses os elementos mais evidentes da utopia, não secundária entre as utopias expressas pelo universo calviniano.

\footnotetext{
${ }^{3}$ Em várias páginas autobiográficas e em entrevistas, Calvino retornou ao período capital para a sua formação. Ver, na seção Italo Calvino, Pagine Autobiografiche, agora em ID Saggi, vol.II, org. Mario Barenghi, Milano, Mondadori, 1995, pelo menos a Autobiografia politica giovanile, p. 2733-2760.
}

Anu. Lit., Florianópolis, v. 20, n. Esp 1, p. 10-23, 2015. ISSNe 2175-7917 
Cesare Pavese, o primeiro reconhecido mestre ${ }^{4}$ de Italo Calvino, demonstra um particular talento estilístico ao construir incipit. Se pense somente na trilogia da Bella estate, na qual os exórdios literários coincidem com a ardente juventude de personagens intencionados a mudar radicalmente o tempo da sociedade burguesa vivendo intensamente a noite, à caça de eventos surpreendentes. Sinais inequivocáveis, já nas primeiras fases, indicam a veleidade, a certeira derrota e em Mulheres sós, a nostalgia de um passado distante e imóvel.

No momento delicado da passagem entre a poesia e a prosa, Pavese faz, no seu $O$ oficio de viver (2005), anotações metodológicas e teóricas de estrutura literária, detendo-se nos exórdios, particularmente importantes pela brevidade do conto.

Está escrevendo os contos conhecidos, sob o título de um dos mais bem-sucedidos, Notte di festa. Não ficou satisfeito. As breves narrações permanecerão em nível de testes laboratoriais, úteis para focar o estilo, vislumbrado também posteriormente, depois que o conto havia "saído" com extrema naturalidade, compacto.

Serão publicados apenas postumamente, o que testemunha a severidade de Pavese com a própria escritura. Juntamente com essas fundamentais anotações, encontramos este trecho 5 :

\begin{abstract}
A única alegria no mundo é começar. É belo viver porque viver é começar, sempre, a cada instante. Quando falta este sentido - prisão, doença, rotina, estupidez - se quer morrer. É por isso que quando uma situação dolorosa se reproduz idêntica pareça idêntica - nada vence o horror. (PAVESE, 1968, p. 57)
\end{abstract}

A coincidência, entre outras características, fecundíssima em todo $O$ oficio de viver (2005), entre reflexão laboratorial sobre a escrita e consequente dedução de um princípio basilar de vida, nos parece significativa.

Sobre o incipit, no sentido amplo, se encontram a experiência estilística (se se pensa aos brevíssimos capítulos de A lua e as fogueiras (1986), sustentados sempre por um incipit de uma qualidade literária altíssima, postos frequentemente, como um longo poema, em

\footnotetext{
${ }^{4}$ Pavese aconselha Calvino a se dedicar ao romance, depois do extraordinário lançamento de $A$ trilha dos ninhos de aranha. Uma escolha também determinante, olhando-a mais à frente no tempo sufocante. Calvino se definirá como escritor de contos, pois não sente dominar aquele texto longo "imposto" por Pavese. De resto, os seus êxitos narrativos são muito distantes daqueles de Pavese, que acaba sendo julgado "distante", ligado às fases do pós-guerra. Ver, entre os artigos e testemunhos sobre o escritor das Langhe, Italo Calvino, Colloquio con Carlo Bo (1960) agora in ID Saggi, vol.II, cit., p. 275-2729. Permito-me remeter ao meu Fabio Pierangeli, Pavese, Calvino, lavorare stanca, in ID, Italo Calvino. La metamorfosi e l'idea del nulla, Soveria Mannelli, Rubettino, 1998, p. 97-117. A importância de $O$ dia de um escrutinador na história da literatura, da cultura e na sociedade italiana em seu desenvolver-se, para além das próprias intenções do autor, colhe-se na introdução do autor à nova edição de Marco Belpoliti, L'occhio di Calvino. Nuova edizione ampliata, Torino, Einaudi, 2006, p. VII-XII.

5 Tradução de nossa autoria N.T.
} 
posição de enjambement estrutural) e aquela cognoscitiva, fruto de uma única reflexão sobre a realidade ${ }^{6}$.

Provavelmente sem a dramaticidade que assume em Pavese, essa exigência (recordem-se das últimas páginas do diário em mérito às duas experiências fundamentais de início: o trabalho criativo e o namoramento), colocada em cheque pela repetição angustiante das sentenças, opostas e complementares, do trágico: aquilo que foi será, aquilo que foi e não será mais, Calvino também exprime, em modalidades mais próximas ao jogo literário, um similar desejo de iniciar sempre.

Releiam-se, neste sentido, duas célebres Notas a Nostri Antenati, de 1960 e ao livro “inicial" A trilha dos ninhos de aranha, de 19647, do qual transcrevo o seguinte trecho, eloquente, seja na sutil ironia, a primeira arma à disposição de Perseu para não se deixar aprisionar em nenhuma definição, mantendo, com todos e tudo, aquela distância, que é um pouco de acanhamento, um pouco de timidez, um pouco de incapacidade de relacionar-se com as mudanças do mundo, depois de ter perdido o centro granítico de uma ideologia ${ }^{8}$, aplicada

\footnotetext{
${ }^{6}$ O próprio Calvino, sob o manto de sua ironia, aqui polêmica e ressentida contra o entrevistador, mostrando toda a sua idiossincrasia (estamos em 1973) para as classificações ideológicas, autoriza indiretamente esta leitura em uma passagem da entrevista a Camon, em Ferdinando Camon, Il mestiere di scrittore, Milano, Garzanti, 1973, agora in Italo Calvino, Saggi, vol.II, cit. p. 2777. Calvino estigmatiza a sua dificuldade oralmente, mas também por escrito para se expressar, para comunicar ideias. Por isso, afirma, tornou-se escritor, com a possibilidade de escrever uma frase por quatro, cinco vezes para encontrar aquela certa. Ideológicas são, principalmente, as frases feitas, aquelas palavras que se empapam na boca, papa pronta, na qual Calvino não tem nenhum interesse. Para concluir "Portanto, eu gostaria que me fizesse algumas perguntas mais empíricas, quem sabe? Pergunte-me qual é o meu critério para começar um conto e qual é o para terminar, e verá que uma ideologia acabará aparecendo, talvez a meu contragosto. Ao invés disso, com as perguntas de "comentários ao texto", é preciso sempre reportar-se a uma data, colocar-se na origem daquele dado escrito, depois transportá-lo para hoje, atualizá-lo... Melhor algumas perguntas atuais, que prescindam da história individual; já que esta depois sempre retorna à superfície". O cursivo está no texto para destacar os dois verbos tão familiares a Calvino na fase de escrita de Se um viajante numa noite de inverno e depois nas anotações das Lições americanas. Dessa forma, a atualidade do texto, da qual se deve sempre partir, a despeito do volumoso eu que sai da história, que, portanto, (quase com lamento) deverá aparecer.

${ }^{7}$ Assim nos ensaios de Assunto Encerrado, publicados pela Einaudi em 1980. Leia-se esta passagem, a propósito do citacionismo, dos gêneros literários, do particular atravessamento dos livros dos outros, que caracteriza Calvino à página 189: "A ironia ariostesca, o cômico shakesperiano, o picaresco cervantino, o humor sterniano, a truanice de Lewis Carroll, de Edgar Lear, de Jarry, de Queneau valem para mim na medida em que, por meio deles, alcançamos essa espécie de distanciamento do específico, de sentido da vastidão do todo" (2009, tradução de Roberta Barni). Coloca-se para completar a operação primária de aperfeiçoamento e atenuação da descrição da realidade na escrita: o tirar peso sinteticamente evocado na primeira das Lições Americanas. Ver, deste ponto de vista, o uso da língua italiana, que tende à exclusão e à subtração, no estudo ainda válido de Pier Vincenzo Mengaldo, Aspetti della lingua di Calvino (1987), agora in ID, La tradizione novecentesca. Terza serie, Torino, Einaudi, 1991, p. 227-291. Para Francesca Serra, Calvino e il pulviscolo di Palomar, Firenze, Le Lettere, 1996, em especial p. 51-71 e 128-145, trata-se de uma operação também psicológica, na direção de continuidade entre estilo e ponto de vista gnoseológico sobre o mundo que levamos em conta para este artigo. De Serra ver também o volume monográfico ID, Italo Calvino, Roma, Salerno editore, 2006 em especial p. 244-256, sobre a imaginação como repertório do potencial.

${ }^{8}$ Ainda nas entrevistas reproduzidas nas interessantes Pagine autobiografiche, aparece, como nos ensaios verdadeiros e próprios, este aspecto. O próprio escritor se força a programas e projetos dos quais logo sente o limite. Por exemplo a Daniele Del Giudice, Paese sera, 7 gennaio 1978, agora in Italo Calvino, Saggi, vol. II, cit, p. 2830: "Cada vez que tento escrever um livro, devo justificá-lo com um projeto, com um programa. Do qual
}

Anu. Lit., Florianópolis, v. 20, n. Esp 1, p. 10-23, 2015. ISSNe 2175-7917 
pelo editor, pelo publicitário, pelo jornalista, na qual a escrita de Calvino, paradoxalmente, jamais se reconheceu:

Este romance é o primeiro que escrevi, quase a primeira coisa que escrevi. O que posso dizer dele, hoje? Direi isto: o primeiro livro, melhor seria nunca tê-lo escrito [...]. Enquanto o primeiro livro não está escrito, possuímos aquela liberdade de

vejo, subitamente, as limitações. Então o aproximo de outro projeto, muitos projetos, e acaba que me bloqueio". Daqui, o desejo de escrever todos os livros possíveis, a ideia do incipit permanente, mas também a crise de Silas Flannery a respeito dos três pontinhos suspensivos do quadrinho de Snoopy. De outro lado, a resposta vem da multiplicidade, da velocidade dos circuitos mentais, do colher a elegância, a leveza, a eficaz precisão de Pégaso. Por este espírito de contínua renovação, pelo menos nas próprias narrações, fundamental é também a entrevista feita por Maria Corti sobre "Autógrafo", em 6 de outubro de 1965 e também esta reproduzida em Italo Calvino, Saggi, cit., pp. 2920-2929, em especial as primeiras páginas. Documento fundamental, do ponto de vista do personagem e biográfico, capaz de projetar uma luz intensa sobre a obra, é o testemunho de Pietro Citati, Ricordo di Calvino, in Italo Calvino. Uno scrittore pomeridiano, intervista sull'arte della narrativa cit., p. 5-20. Citati, companheiro de longa data de Calvino, tinha em comum com o escritor as estadias no mar da Riviera di Ponente do Sul da França e daqueles encontros reconstrói o longo percurso da sua atividade, até as dolorosas páginas da morte repentina, com a aparição em sonho nos dias imediatamente sucessivos. Todo o testemunho é extremamente importante para situar as fronteiras de um escritor solitário, até mesmo intimidado pela realidade, totalmente parecido com seu Palomar: não falava nunca com prazer de psicologia, não lhe interessava nos seus personagens. A literatura para ele era "coisa mental" (totalmente oposta, portanto - como em diversas alusões, em nosso congresso, destacaram Maria Betânia e Andrea Lombardi - dos expressionistas e de Pasolini), lhe repugnava fortemente dizer eu, ao ponto de tornar-se, ao final de sua carreira de escritor, conscientemente, um ser coletivo, uma espécie de recipiente: incerto, perplexo, inquieto, sujeito às mínimas sugestões da atmosfera. (Sobre estes argumentos, como recordado por Maria Betânia, ver Carla Benedetti, Pasolini contro Calvino. Per una letteratura impura, Torino, Bollati Boringhieri, 1998). Para o tema do incipit como início, são interessantes as sugestões de Benetti nas páginas 63-86, nas quais aproxima o conto cosmicômico Um sinal do espaço ao Prefácio a A trilha dos ninhos de aranha, ambos de 1964. Citati capta bem a mudança de Calvino na metade dos anos Cinquenta, nas fases descritas em $O$ dia de um escrutinador: um fechamento quase completo para com a realidade, a construção da imagem de um homem-literatura, todavia muito influente e de sucesso, "a sua mente se transformou. Tornou-se a mais complicada, a mais envolvente, a mais sinuosa, labirintica mente que um escritor italiano já possuiu" (p. 14), seguidor de novas conjecturas, de novos estudos das infinitas possibilidades escondidas em um dato fenômeno ou em uma dada experiência. "Se, algum dia, havia amado a obstinada teimosia da linha reta, agora preferia os entrelaçamentos, as linhas tortuosas e ramificadas. Se, algum dia, o ritmo era velocíssimo e aventureiro, agora o seu tempo era lento, prudente, meticuloso, como se dissesse, depois apagasse, acrescentasse, retocasse, se contradissesse: e cada tema se desenvolvia em um cortejo de contradições" (p. 15). Na bela entrevista de Weaver, entre as outras respostas interessantes, sempre irônicas e propensas a dar uma imagem difusa, como se estivesse distante, Calvino reforça a importância da estrutura dos seus últimos livros. A ideia do romance não o fascina, prefere as coletâneas de contos, unidas nos modos diversos, por exemplos, nos três livros exemplares: Castelo dos destinos cruzados, As cidades invisíveis, Se um viajante numa noite de inverno. De tais breves contos, cada um tem um momento de início, nítido, que os possa distinguir na sólida arquitetura, perfeita e exaustivamente pensada. Obviamente, acrescenta Calvino, esta exaustão não deve, de fato, chegar ao leitor, mas diz respeito ao laboratório de escrita. Normalmente o seu método de escrita de tais contos prevê uma pequena imagem única que vem ampliada em seguida, no próprio ato de escrever (sempre cheio de correções e revisões). Extremamente interessante é a seguinte informação, propriamente a respeito de $O$ dia de um escrutinador e da relação entre política e literatura depois dos anos de ativismo comunista, p. 62: "Me sentia obrigado a aceitar muitas coisas que estavam muito distantes do meu modo de sentir. Em seguida, comecei a perceber uma crescente incompatibilidade com a ideia de construir na Itália uma democracia real servindo-se do modelo e do mito da Rússia. A contradição torna-se tão grande que me senti lançado fora do mundo comunista, e por fim, da política. Foi uma sorte. A ideia de colocar a literatura em segundo lugar em relação à política é um grande erro, porque a política jamais atinge os seus ideais. A literatura, ao invés disso, na sua pequenez, pode atingir qualquer resultado e, a longo prazo, também ter efeitos práticos: agora passei a acreditar que as coisas importantes se alcançam somente através de processos muito lentos". A ideia da inicialidade, direcionando estas afirmações na nossa temática, realiza-se evidentemente no jogo literário, no lirismo atrelado na moldura matemática das Cidades invisíveis, como nas invenções paradoxais e medidas dos incipits de $\mathrm{Se} u m$ viajante numa noite de inverno, para ficar com os textos mais bem-sucedidos, que o próprio Calvino cita como os seus melhores livros naquela entrevista.

Anu. Lit., Florianópolis, v. 20, n. Esp 1, p. 10-23, 2015. ISSNe 2175-7917 
começar que se pode usar uma única vez na vida, o primeiro livro já define você, ao passo que na realidade você ainda está longe de ser definido; e essa definição, depois você terá de carregá-la ou corrigi-la ou desmenti-la, mas não conseguindo nunca mais abrir mão dela. (CALVINO, 2004, p. 23)

Um primeiro livro, aquele exórdio, ligado à atmosfera de ativismo apaixonado em direção a um ideal compartilhado de reconstrução depois da guerra civil, descrito em $O$ dia de um escrutinador, sentido, somente uns quinze anos depois, como um insuperável diafragma. Descobre-se a outra face do exaltante início, a sombra que caminha a seu lado: a separação violenta do lugar indefinito, da posição privilegiada na qual se prevêem todas as estradas possíveis, as cidades da utopia.

Eis ainda um trecho da Nota de 1964, na qual Calvino se lamenta de não ter mais esta possibilidade de um início incontaminado, gerado do nada, como os primeiros passos sobre uma neve cândida, ou o primeiro gesto de um homem no cosmo recém-nascido. Não precisa subestimar a dose de ironia e de jogo literário que acompanham sempre as mais sérias reflexões sobre o ofício de escrever. Notem-se as mesmas imagens do trecho do Escrutinador citado na abertura de uma experiência exaltante da qual não resta nada além de uma fraca recordação, totalmente análogas àquelas iniciais das Notas a Os Nossos antepassados e não diferentes, em diversos contextos históricos, no decretar o fim de uma experiência, na introdução a Assunto Encerrado e ao exórdio sentencioso da conferência americana, depois descartada, Cominciare e finire ${ }^{9}$ :

\begin{abstract}
Dessa violência que você lhe fez ao escrever, a memória nunca mais se recobrará: as imagens privilegiadas vão permanecer queimadas pela promoção precoce a temas literários, ao passo que as imagens que você quis guardar, talvez com a intenção secreta de utilizá-las em futuras obras, definharão, porque ficaram de fora da integridade natural da memória fluída e viva [...]. O escritor dá por si como o mais pobre dos homens [...]. Assim olho para trás, para aquela temporada que a mim se apresentou repleta de imagens e significados: a guerra partigiana, os meses que contaram como anos e dos quais, por toda a vida, deveria ser possível continuar puxando rostos e advertências e paisagens e pensamentos e episódios e palavras e emoções: e tudo é distante e nebuloso, e as páginas escritas estão ali em descarada segurança, que bem sei ser enganadora, as páginas escritas já polemizando com uma memória que ainda era um fato presente, maciço, que parecia estável, que havia se dado de uma vez por todas, a experiência, - que já não me adiantam, precisaria de todo o resto, justamente de aquilo que não está lá. Um livro escrito nunca me consolará daquilo que destrui ao escrevê-lo: aquela experiência que, guardada por todos os anos da minha vida, talvez tivessem me servido para escrever o último livro e me bastou apenas para escrever o primeiro. (CALVINO, 2004, p. 24-25)
\end{abstract}

\footnotetext{
9 “Começar uma conferência, principalmente um ciclo de conferências, é um momento crucial, como começar a escrever um romance. É este o momento da escolha: nos é oferecida a possibilidade de dizer tudo, em todos os modos possíveis e devemos dizer alguma coisa, em modo particular". Italo Calvino, Appendice. Cominciare e finire (1992a), in ID., Saggi, vol. I, a cura di Mario Barenghi, Milano, Mondadori, p. 734. Começar é, portanto, também o "medo" de escolher, o distanciamento da potencialidade ilimitada.
}

Anu. Lit., Florianópolis, v. 20, n. Esp 1, p. 10-23, 2015. ISSNe 2175-7917 
O percurso das coletâneas dos contos cosmicômicos se delineou em torno às teorias cosmogônicas, percebido como o lugar ainda não definido por completo, a começar pela voz narrativa que não tem um nome legível e assume o papel de presença a-histórica. Um lugar onde se flutua "em um campo de probabilidades, tomando emprestadas e restituindo cargas de energia todas ainda hipotéticas" (CALVINO, 2007, p. 342) ${ }^{10}$, como se lê no fragmento mais próximo às temáticas do começar e terminar, O nada e o pouco, na ideia de poder contar o primeiro segundo da história universal.

$\mathrm{Na}$ semiologia, na literatura combinatória no seu entrelaçar-se com a cena, nos jogos dos solidários escritores franceses, Calvino reencontra e desenvolve o elemento da potencialidade, em livros como $O$ castelo dos destinos cruzados $^{11}$ e As cidades invisíveis, nos quais, dentro da ambientação resgatada na tradição literária, a memória pessoal se fixa sobre microcontos nos quais os incipits devem ser necessariamente significativos.

Explicitamente, o hiper-romance Se um viajante numa noite de inverno dedicado a estas temáticas se move propriamente em torno da ideia do início, no diário do escritor em crise Silas Flannery. O primeiro título dado por Calvino ao romance em construção é propriamente Incipit.

$\mathrm{Na}$ Nota do organizador da edição dos Meridiani, Bruno Falcettoaponta oensaio "La squadratura" [O enquadramento], dedicado à pintura do amigo Giulio Paolini, um verdadeiro e próprio esboço, no qual facilmente se reconhecem as perplexidades e as meditações de Silas Flannery, como já havia intuído Cesare Segre. Do ensaio, introdução a uma coletânea de pinturas de Paolini ${ }^{12}$, existe uma versão mais ampla, no qual muitos são os elementos em

${ }^{10}$ Leia-se na página seguinte: "É natural que pertencer a esse universo sem precedentes em termos de comparação se tornasse logo motivo de orgulho, de jactância, de paixão. O escancaramento fulmíneo de distâncias inimagináveis, a profusão de corpúsculos que jorravam por todo lado - hádrons, bárions, mésons, alguns quarcks -, a rapidez precipitada o tempo, tudo isso junto nos dava uma sensação de invencibilidade, de domínio, de orgulho, e ao mesmo tempo de presunção, como se tudo nos fosse devido". Se o confronto era com o nada primeiramente, acrescenta o solitário Qfwfq, o todo era o nosso elemento, o todo era o mais. Uma energia primordial, descrita quase como último ato da narrativa calviniana, no mesmo momento, idealmente, no qual o seu Palomar morre, torna ao início, isto é, ao todo (potencial). O equilíbrio, porém, também nesta "nova" cosmicômica dura pouco, constrangida a confrontar-se com sentimentos opostos, tais como o senso de precariedade e a indiferença, representada por uma personagem feminina, Nugkta. Talvez tenha sido uma falsa partida.

${ }^{11}$ Ver a interpretação do incipit do conto moldura de Giorgio Bárberi Squarotti, Dal Castello a Palomar: il destino della letteratura, in Italo Calvino. Atti del Convegno internazionale, Firenze, 1987, Milano, Garzanti, 1988, p. 329-335, exemplar para o discurso de toda a estação da literatura combinatória, estruturado com a premissa canônica de uma aventura, de um livro de fábulas que, ao invés disso, conduz à consciência da afasia, combatida com a repetição material de imagens, propriamente na convicção, para o notório ensaísta, trágica, que não existe mais nada para inventar. Definitivamente, retorna a obsessão de Pavese, a angústia das sentenças bíblicas ("nada de novo sob o sol") à qual se opõe a ética da literatura como jogo ou hiper-romance.

${ }^{12}$ Ver sobre o ensaio dedicado a Paolini, Marco Belpoliti, L'occhio di Calvino, p. 159-167 e Letizia Lodi, I colori della mente. Italo Calvino; scritti sulle arti (1970-1985), in Italo Calvino, la letteratura, la scienza, la città, a cura di Giorgio Bertone, Genova, Marietti, 1988, p. 141-154 (sobre Paolini, 147-148).

Anu. Lit., Florianópolis, v. 20, n. Esp 1, p. 10-23, 2015. ISSNe 2175-7917 
comum com o romance. Em particular: "No Enquadramento [squadratura] descartado estão já em foco as principais ideias motrizes do Viajante. Antes de qualquer coisa, o motivo do incipit como quintessência da potencialidade da literatura".

Bruno Falcettotambém cita a passagem de $O$ dia de um escrutinador, unindo a pesquisa literária do Calvino da segunda metade dos anos setenta, com a inquietude dos primeiros anos da década de sessenta ${ }^{13}$.

Aquilo que para o pintor é o enquadramento da tela, para o escritor é o incipit, a fórmula de abertura que pode ser anônima, de repertório, o alfa de toda possível ficção escrita, não ainda propriamente a ficção, mas o aviso que se está entrando na ficção. (FALCETTO, 1992b, p. 1383)

Eis aqui, como depois na passagem celebríssima do diário de Silas Flannery, com Snoopy atento a admirar o seu incipit "anônimo e potencial", "Era uma noite escura e tempestuosa..." (Calvino, 1990, p. 180), o lugar circunscrito da potencialidade, não ainda ficção, mas em algum modo já um romance. Mais ainda são os três pontinhos a exprimir tal possibilidade, no jogo sutil de Calvino: a máxima suspensão possível, dentro de uma banal pontuação, de repertório, de serviço.

Os limites consentidos por este ensaio não nos permitem concentrar-nos em Se um viajante numa noite de inverno, objeto de amplos estudos ${ }^{14}$, no qual Calvino, pelo menos no campo restrito dos livros (no qual, entre outras coisas, há tempo estava concentrada a sua ação ética e humanística), realiza o desejo de escrever um livro, dentro de uma moldura, formado somente de inícios de romances, cujos títulos, colocados juntos, formam, de fato, um formidável início potencial, suspenso como aqueles três pontinhos do Snoopy, divagante, fluído, no meio das gaiolas e das armadilhas dos gêneros literários construídos pelos críticos.

Recordarei somente, no trecho seguinte aquele do poster do Snoopy, sempre inserido no diário de Silas Flannery, como a ação do escritor em crise decidido a agarrar a carga de energia (ainda esta palavra extremamente conotada) de um incipit autoral, para ver se pode comunicar-se com a sua mão, desbloqueando a sua hipertrofia, termina por transformar-se no copista de um grande trabalho: Crime e Castigo.

Seria bonito, vislumbrado um modelo, poder somente copiá-lo, abandonar-se à sua grandeza: o escritor se transformaria em leitor, sem mais a ânsia e a obsessão de mostrar-se diferente.

\footnotetext{
${ }^{13}$ Tradução de nossa autoria N.T.

${ }^{14}$ Sobre essas problemáticas ver Mario Barenghi, Italo Calvino, le linee e i margini, Bologna, Il Mulino, 2007, em especial p. 61-81.
}

Anu. Lit., Florianópolis, v. 20, n. Esp 1, p. 10-23, 2015. ISSNe 2175-7917 
Por um instante, pensei compreender qual deve ser o sentido e o encanto de uma vocação até agora inconcebível para mim: a de copista. O copista vivia simultaneamente em duas dimensões temporais, a da leitura e a da escrita; podia escrever sem a angústia do vazio que se abre diante da pena; ler sem a angústia de que seu próprio ato não se concretize em algum objeto material. (CALVINO, 1990, p. 180)

Como se vê, o terror de ser definido, explodido ironicamente naNotaaoNa trilha dos ninhos da aranha, retorna nesta angústia de ver materializadas, e portanto queimadas, as ideias potenciais, aqueles três pontinhos suspensivos tão excitantes, a prova da fascinação dos romances.

Para não cair na parábola degradante de um incipit ao qual não se segue uma realização adequada àquela fascinação, dever-se-ia saber escrever um livro total, ou seja, capaz de conter todos os livros que o leitor espera ler. Acionar todas as potencialidades possíveis, não desativá-las em parcialidades feias e extenuantes.

Ao se transportar este mecanismo do mundo narrado ao mundo natural entra-se na busca de Palomar, livro que se formou lentamente nos mesmos anos que Se um viajante numa noite de inverno: tendo descoberto que o universo é feito de instantes, encaminha-se, lentamente, para conhecê-los e, quem sabe, escrever, o grande livro do mundo natural.

Dois paradoxos, dois lados da mesma moeda para resolver a urgência de duas questões que aparentemente formam dois opostos: o incipit como entrada em um universo criado naquele momento, a potencialidade, a totalidade da consciência ainda intactas.

No entanto, Calvino realizou o desejo do seu alter ego Silas, perenemente em crise por estar angustiado de ter que escrever livros sempre diferentes, para não ser rotulado, para vencer o desafio ao labirinto do tédio, da estagnação. Trata-se, em suma, de um espelho da literatura que olha a si mesma. Um incipit realizado para fechar um ciclo, como compreendido no Enquadramento [squadratura], o diário de Silas não é nada além da mise em abyme da metanarrativa:

\footnotetext{
Veio-me a ideia de escrever um romance feito só de começos de romances. O protagonista poderia ser um Leitor que é continuamente interrompido. O Leitor adquire o novo romance A do autor Z. Mas é um exemplar defeituoso, e ele não consegue ir além do início... O leitor volta à livraria para trocar o volume...

Poderia escrevê-lo todo na segunda pessoa: você, Leitor... Poderia também incluir uma Leitora, um tradutor falsário, um velho escritor que mantém um diário similar a este... (CALVINO, 1990, p. 202)
}

A primeira das Lições Americanas devia retomar estas temáticas na perspectiva de uma história das narrativas catalogadas pelos incipits, pela invocação proemial, através do princípio de identidade do romance dos séculos XVIII e XIX, para chegar à tendência enciclopédica do século XX. Calvino, depois de ter trabalhado intensamente, em duas versões 
diferentes, a descarta, julgando-a, provavelmente, muito heterogênea e pouco eficaz em nível comunicativo.

Alguns materiais, se a morte, o fim terreno, não o tivesse bloqueado, fluiriam na sexta lição, Consistência, mas diversas pistas se encontram nas cinco lições publicadas.

O título hipotético era o mais simples e significativo: Cominciare e Finire (Começar e Terminar $)^{15}$. A redação da lição foi publicada como Apêndice às Lezione americane nos Meridiani e se insere perfeitamente nas temáticas mencionadas da consciência universal e pulviscular do último Calvino e do seu Palomar, retomando a hipótese bipolar da Nota à Trilha: de uma parte o doloroso afastamento (de resto, o conto é uma forma precisa surgida do tempo no qual temos à disposição o mundo), de outra, a fascinação do potencial, em um tipo de inextricável continuidade de partidas narrativas que faz de Calvino um narrador de short stories $^{16}$, consideradas, definitivamente, verdadeiros e próprios organismos, leves e flutuantes, quem sabe dentro de um "enquadramento" que as mantém juntas. E o que são as short stories se não a invenção de um incipit, uma brevíssima narração e um final de efeito? Começar e terminar, colocar um pé na neve fresca para subitamente retirá-lo, escolhendo uma outra paisagem incontaminada: "Isto é particularmente verdadeiro para os romances: é como se no momento do início o romance sentisse a necessidade de manifestar toda a sua energia" (Calvino, 1992, p. 180).

\footnotetext{
${ }^{15}$ Ver Mario Lavagetto, Dovuto a Calvino, Torino, Bollati Boringhieri, 2001, Per l'identità di uno scrittore di apocrifi, p.13-34 para a leitura de Se um viajante numa noite de inverno e Little is left to tell, p. 87-116, a propósito de Cominciare e Finire, interessantíssimo ao comentar uma passagem de Calvino a propósito da menção a Beckett que fechava o ensaio: o escritor desconstrói o sentido, deixando, porém, que aquela verdade aflore entre as linhas: trata-se da própria possibilidade de contar em equilíbrio instável esta controversa interpretação, para o grande dramaturgo irlandês não é mais possível (não obstante o jogo dos incipits), para Calvino talvez sim (p. 92): "Calvino, por sua vez, no momento decisivo parece recusar-se (ou ser incapaz) de registrar aquela sentença. A peça é reescrita; a sentença transformada em um conto: o autor contou o exaurir-se das histórias, mas um conto não abolirá nunca os outros contos. Permanecerá, pelo menos, um outro conto que a um desenvolvimento linear e irrevogável, à narração de como se fecha a última fenda, substituirá um desenvolvimento circular: o início é idêntico ao final, enxerga-se um buraco e o livro ainda está aberto sobre a mesa ou, pelo menos, eternamente mal fechado". O esforço de Calvino seria propriamente o novo início, o recomeçar da literatura, a sua reinaiguração, talvez a partir do pouco, como argumenta Lavagetto, fazendo de Calvino "o poeta daquele pouco".

${ }^{16}$ Leia-se um trecho de Cominciare e Finire em Italo Calvino, Saggi, vol. I, cit. p. 751, que depois de ter descrito o incipit como a divisão da multiplicidade das possibilidades e vice-versa, o ingresso em um mundo completamente diferente, o lugar literário por excelência, conclui: "Preferi falar de particular e de multíplice, ou melhor, de "parte" e de "todo", porque "todo", "totalidade", são palavras das quais sempre desconfio um pouco. Não pode existir um todo dado, atual, presente, mas somente uma poeira de possibilidades que se unem e separam". Somente a obra literária se organiza em uma forma, com um incipit e um explicit bem delineados, nos quais adquire um sentido, não definitivo, não rígido, mas "vivo como um organismo". Esta última palavra, já usada no trecho citado no ínicio, de $O$ dia de um escrutinador: graças à literatura, a obra, ou melhor, as short stories, são organismos que não estão sujeitos à rotina cotidiana, ao olhar petrificante de Medusa.
}

Anu. Lit., Florianópolis, v. 20, n. Esp 1, p. 10-23, 2015. ISSNe 2175-7917 


\section{Referências}

BERTONE, Giorgio (Org.) Italo Calvino, la letteratura, la scienza, la città. Genova: Marietti, 1988.

CALVINO, Italo. Appendice. Cominciare e finire, in ID., Saggi, vol. I. Milano: Mondadori, 1992.

Letras, 2004.

A trilha dos ninhos de aranha. Trad. de Roberta Barni. São Paulo: Companhia das 2002.

. O dia de um escrutinador. Trad. de Roberta Barni. São Paulo: Companhia das Letras,

. Se um viajante numa noite de inverno. Trad. de Nilson Moulin. São Paulo: Companhia das Letras, 1990.

. Todas as cosmicômicas. 1.ed. Trad. de Ivo Barroso e Roberta Barni. São Paulo: Companhia das Letras, 2007.

FALCETTO, Bruno. Note e notizie sui testi, Se una notte d'inverno un viaggiatore. In: Italo Calvino, Se una notte d'inverno un viaggiatore, in ID, Romanzi e racconti, vol. II. Milano: Mondadori, 1992.

PAVESE, Cesare. A lua e as fogueiras. Trad. de Sérgio Lamarão. Rio de Janeiro: Guanabara Dois, 1986.

. Il mestiere di vivere. Torino: Einaudi, 1968.

1988.

. Mulheres sós. Trad. de Júlia Marchetti Polinesio. São Paulo: Editora Brasiliense, 2005.

. O oficio de viver. Trad. de Alfredo Amorim. Lisboa: Editora Relógio d'Água,

WEAVER, William; PETTIGREW, Daniel (Orgs.). Italo Calvino, Uno scrittore pomeridiano, intervista sull'arte della narrativa. Roma: Minimum fax, 2003.

\section{Italo Calvino and the energy at "the starting moment"}

Abstract: The incipit, as narrative exordium, as the literary structure whereupon Calvino reflects, contains the kernel of a subtle utopia: to find oneself always at the onset, at the creative spot where anything is possible, and wherefrom energies emanate and retreat. The starting point, which stands for the cornerstone of any literary project, becomes an experience that is directly associated with the individual and with his/her social-political action. The incipit might be considered, at the same time - making use of a term from stylistic criticism a literary archetypal protothema. The "utopian ideal" would consist in the continuous enlargement of this initial energy as for a compact, coherent, well defined, and, still, alwaysnew organism to be shaped. Always more consciously, as the essay Cominciare e Finire [Beginning and ending] from February 1985 poses, such idea permeates Calvino's stylistic 
choices, in his constant trajectories' alterations, in the horror of being classified within one of the intellectual "cages" of literary genres.

Keywords: Italo Calvino. Incipit. Potential energy. Organism.

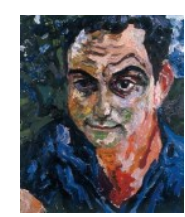

